IZA DP No. 6219

Competition, Group Identity, and

Social Networks in the Workplace:

Evidence from a Chinese Textile Firm

Takao Kato

Pian Shu

December 2011 


\title{
Competition, Group Identity, and Social Networks in the Workplace: Evidence from a Chinese Textile Firm
}

\author{
Takao Kato \\ Colgate University, CJEB (Columbia), \\ TCER (Tokyo), CCP (Aarhus) and IZA
}

Pian Shu

MIT

\section{Discussion Paper No. 6219 \\ December 2011}

\author{
IZA \\ P.O. Box 7240 \\ 53072 Bonn \\ Germany \\ Phone: +49-228-3894-0 \\ Fax: +49-228-3894-180 \\ E-mail: iza@iza.org
}

\begin{abstract}
Any opinions expressed here are those of the author(s) and not those of IZA. Research published in this series may include views on policy, but the institute itself takes no institutional policy positions.

The Institute for the Study of Labor (IZA) in Bonn is a local and virtual international research center and a place of communication between science, politics and business. IZA is an independent nonprofit organization supported by Deutsche Post Foundation. The center is associated with the University of Bonn and offers a stimulating research environment through its international network, workshops and conferences, data service, project support, research visits and doctoral program. IZA engages in (i) original and internationally competitive research in all fields of labor economics, (ii) development of policy concepts, and (iii) dissemination of research results and concepts to the interested public.
\end{abstract}

IZA Discussion Papers often represent preliminary work and are circulated to encourage discussion. Citation of such a paper should account for its provisional character. A revised version may be available directly from the author. 


\section{ABSTRACT \\ Competition, Group Identity, and Social Networks in the Workplace: Evidence from a Chinese Textile Firm*}

Using data on team assignment and weekly output for all weavers in an urban Chinese textile firm between April 2003 and March 2004, this paper studies a) how randomly assigned teammates affect an individual worker's behavior under a tournament-style incentive scheme, and b) how such effects interact with exogenously formed social networks in the manufacturing workplace. First, we find that a worker's performance improves when the average ability of her teammates increases. Second, we exploit the exogenous variations in workers' origins in the presence of the well-documented social divide between urban resident workers and rural migrant workers in large urban Chinese firms, and show that the coworker effects are only present if the teammates are of a different origin. In other words, workers do not act on pecuniary incentives to outperform teammates who are from the same social network. Our results point to the important role of group identities in overcoming self-interests and facilitating altruistic behavior.

JEL Classification: M5, J24, L2

Keywords: coworker effects in the workplace, social networks, intergroup competition

Corresponding author:

Takao Kato

Department of Economics (Persson 222)

Colgate University

13 Oak Drive

Hamilton, NY 13346

USA

E-mail: tkato@colgate.edu

\footnotetext{
* The data were collected in collaboration with Xiao-Yuan Dong and Derek C. Jones to whom we are most grateful (see Dong, Jones and Kato, 2007 for details on the data). We benefitted greatly from comments from Joshua Angrist, David Autor, Michael Greenstone, Cheryl Long, Alan Manning, Matt Notowidigdo, Bruce Weinberg, Lan Shi, Nachum Sicherman, David Cooper as well as seminar participants at the 2010 EALE/SOLE meeting (London), the 2010 TPLS meeting (UC-Santa Barbara), Aarhus University, Queen's University, Syracuse University, Universidad Carlos III, Madrid, and University of Lyon. The current version of the paper was completed while Kato was Otto Mønsted Visiting Professor at ASB (Aarhus School of Business), and Kato is grateful for their hospitality.
} 


\section{Competition, Group Identity, and Social Networks in the Workplace: Evidence from a Chinese Textile Firm}

What happens within the firm used to be a black box for mainstream labor economists (Gibbons, 1997). In the last two decades or so, diverse attempts have been made to expand its traditional scope of inquiry to include institutions and activities inside the firm. On the one hand, the literature on promotion tournament (pioneered by Lazear and Rosen, 1981) has provided new insight on the nature and scope of competition among coworkers within the firm, facilitated by promotion tournament. On the other hand, the growing literature on economics of human resource management practices has been focusing on coworker cooperation (for instance, knowledge sharing and peer monitoring), and the effects on such coworker cooperation of various human resource management practices (see Ichniowski and Shaw, 2008 for a most recent review). In this paper we join forces in such efforts to open the black box of the firm by shedding new light on the potentially important role that group identity may play in promoting (or limiting) coworker cooperation and competition in the workplace.

Specifically, using weekly data for defect rates (proportion of defective output) for all weavers in a Chinese textile firm during a 12 months (April 2003-March 2004) period, this paper provides evidence on the presence and nature of coworker effects (individual worker behaviors influenced by the teammates' behaviors or characteristics) in the manufacturing workplace. ${ }^{1}$ First, we find that a worker increases her effort level and improves her performance when working with more able teammates. Second, by exploiting the well-documented fact that an exogenously-

\footnotetext{
${ }^{1}$ Notable recent studies on such coworker effects are either laboratory experimental studies (e.g., Falk and Ichino, 2006) or econometric case studies of workers in the non-manufacturing workplace. For example, Mas and Moretti (2009) use individual productivity data on supermarket cashiers at a large supermarket chain in California and provide direct evidence on performance spillovers though peer pressure. Bandiera, Barankay and Rasul (2010) use individual productivity data on fruit pickers at a leading U.K. agriculture firm and show that workers tend to conform to their friend's productivity level. Guryan, Kroft and Notowidigdo (2009) exploit random groupings of professional golfers and test the presence of coworker effects in professional golf tournaments. Unlike the first two studies, they find no evidence for coworker effects.
} 
formed deep divide between urban resident workers and rural migrant workers exists in firms in Chinese cities, we find novel evidence on the interplay between social networks (urban resident group and rural migrant group) and the coworker effects --- a worker puts in more effort when working with more able outgroup teammates but not when working with more able ingroup teammates.

Economists have been increasingly aware of the potentially important behavioral effects of group identities (see for example Akerlof and Kranton, 2000), and have started to contribute fresh evidence to an already rich body of evidence accumulated by psychologists. ${ }^{2}$ Most of the evidence is from experiments in laboratory settings, and field evidence from the actual workplace is rare. For instance, Chen and Li (2009) first induced group identities to their subjects in laboratory settings and let them play a series of two-person sequential games. The interplay between group identities and outcomes from such games indicates that group identities indeed facilitate altruistic behaviors by subjects. Our weavers display similar group identityinduced altruistic behaviors in the actual workplace when competing with their teammates in the presence of relative performance-based incentives (pecuniary incentives to outperform their teammates in the form of wage increase and prize). Specifically our weavers are found to not act on such incentives to outperform their teammates insofar as the source of the rising average ability of her teammates (and hence increased coworker competition) is the presence of more able ingroup teammates. In other words, our weavers appear to be willing to let their teammates win the prize and earn higher wages insofar as they belong to the group with which they strongly identify. Such altruistic behaviors do not arise, however, if the rising average ability of their teammates comes from more able outgroup teammates. In short, we interpret our finding (significant coworker effects arise across the social network yet not within) as evidence from the

${ }^{2}$ For a succinct literature review including both social psychology and economics, see for instance Chen and Li (2009; section 1). 
actual workplace on the important role that group identities play in overcoming self-interests and facilitating altruistic behaviors in the presence of pecuniary incentives to outperform teammates.

\section{Data and Setting}

The Chinese textile firm in our case study, SCT, is based in Shijiazhuang, an industrial city and the capital of Hebei province in the northeastern China. ${ }^{3}$ Textile is one of the city's most prosperous industries. SCT was founded in 1921, originally as a state-owned enterprise (SOE). However, like many other large SOEs, SCT suffered from the financial crisis during the 1990's due to outdated facilities, an aging workforce, and shrinking market. In 1998 the firm was one of the first large-scale SOEs to be privatized. The ownership and management restructure saved the firm from the threat of bankruptcy. SCT employed about 3,500 workers during our study period.

In collaboration with Xiao-Yuan Dong and Derek C. Jones, we collected several kinds of data from the case. ${ }^{4}$ These were collected during a lengthy study period, highlighted by two separate site visits with extensive interviews with the Director of Human Resources, the Director of the Weaving Division, a line supervisor and two team leaders at the Weaving Division, and the Director of Data Management (who was in charge of all internal data). In addition, to get perspective from an outsider, the site visit was supplemented by an extensive interview with a long-term consultant for SCT who has been observing the firm for many years. As well as collecting various performance and personnel data, we also deepened our knowledge of the case by collecting data from a survey that we designed and administered to all team leaders.

The detailed personnel data with which SCT generously provided us include personal characteristics, weekly performance measures and wage for all of its weavers in the weaving division over the 53-week span between March 2003 and April 2004. An advantage of this

\footnotetext{
${ }^{3}$ Our confidentiality agreement with SCT prohibits us from revealing the actual name of the firm.

${ }^{4}$ See Dong, Jones and Kato, 2007 for details on the data.
} 
"insider" dataset is that the individual performance measures are recorded by machines and thus measured with little errors. For the purpose of this study, we dropped 12 weavers who have worked for only 1 week as well as 115 observations where the weaver worked for less than 2 days of the week, for we have too little data to accurately predict abilities for these weavers. They are also unlikely to receive or cause any coworker effects with such short presence in the team. The resulting dataset has 9966 observations for 287 individual weavers. ${ }^{5}$ Table 1 provides the summary statistics of their personal characteristics. All but 9 weavers are female. They all have graduated from junior high school but not high school. About $67 \%$ of them are rural migrant workers, while the rest are urban resident workers.

A quick glance at the workplace gives observers a first impression that the role of weavers in the production process is rather limited since the operation appears to be fully automated. Cloths are produced by automated looms rather than weavers. However, a longer and closer observation of the workplace reveals that automated loom machines are far from perfect and that problems do occur from time to time (such as broken threads). ${ }^{6}$ Each weaver's main task is to pay close attention to her assigned loom machines (multiple loom machines are assigned to each weaver) and minimize the occurrence of such operational problems; and if problems arise, solve the problems quickly and effectively.

For example, "good weavers” will detect early signs of problems and make timely adjustments to the operation process so that problems will not fully materialize and hence no defective product will result. Should problems actually turn up, “good weavers” will solve them

\footnotetext{
${ }^{5}$ In addition, one outlier observation was dropped, where its defect rate was above $10 \%$ (the maximum in the rest of data is $2.5 \%$ ) and its daily output was only 5 meters (the mean in the rest is around 500 meters).

${ }^{6}$ Integrating careful field research into standard econometric analyses is a key element of "insider econometrics" (Bartel, Ichniowski and Shaw, 2004). For a compelling demonstration of the value of conducting careful field research before embarking on quantitative research, see Ichniowski, Shaw and Prennushi (1997).
} 
in a timely and effective manner so that defective output will be minimized. Due to the problem solving nature of their main task, SCT constantly tells their weavers how important quality is, and asks them to work toward "zero defect".

For each weaver in each week, the firm keeps three performance-related records: total output produced, days worked, and defective output produced. From these three variables, we calculated the following two performance measures: ${ }^{7}$

Defect Rate (quality measure) of weaver $\mathrm{i}$ in week $\mathrm{t}$ :

(1) DefRate $_{i t}=\left\{\left(\right.\right.$ Defective Output $\left._{\mathrm{it}}\right) /\left(\right.$ Total Output $\left.\left._{\mathrm{it}}\right)\right\} \times 100$;

Average Daily Nondefective Output (quantity measure) of weaver i in week t:

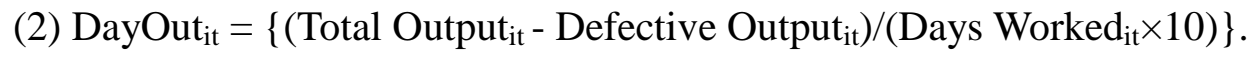

Table 1 shows the summary statistics of the performance measures. The mean of Days Worked $\mathrm{d}_{\mathrm{it}}$ is 6.3 days (a day is counted as an 8-hour work period, so it's possible for the maximal Days Worked $_{\text {it }}$ to exceed 7). The mean of DayOut ${ }_{\text {it }}$ is around 545 meters with standard deviation of roughly 180 meters. The mean of DefRate ${ }_{i t}$ is approximately $0.24 \%$ with standard deviation of 0.18\%. Although "zero defect" is emphasized in the workplace, there doesn't exist a week where zero defect rate is actually achieved.

The nature of weaving technology and the problem-solving nature of a weaver's job at SCT as described above suggests that the key individual performance variable for weavers at SCT is DefRate ${ }_{i t}$ (quality), and while their discretionary efforts matter significantly for DefRate ${ }_{i t}$, there appears to be little room for discretion in terms of pace of production (or DayOut $\mathrm{t}_{\mathrm{it}}$ ). All weavers are required to fulfill planned output levels and they appear to do so on most occasions. ${ }^{8}$

\footnotetext{
${ }^{7}$ The variables are scaled so that the regression coefficients are more readable: daily output is measured in 10 meters and defect rate is out of 100 .

${ }^{8}$ Based on demand for its output, at the beginning of each week, SCT comes up with the upcoming week's detailed production plan with specific numbers for planned output, days worked, and defective output assigned to each individual weaver. The correlation between the planned and actual daily output is 0.9562
} 
In other words, on the one hand, DayOut it is largely determined by the plan, and there will be very little if any room for weavers to have behavioral response to coworker effects. Our wage regressions reported later also confirm that there is no monetary incentive to produce more than planned. Furthermore, it is difficult if not impossible to identify any coworker effects when the output of the whole team is influenced by some aggregate demand shocks.

On the other hand, the weavers have considerable discretion and monetary incentive to minimize defective output, and hence behavioral responses to coworker effects in the quality measure are clearly plausible. Therefore, our investigation of coworker effects will focus on defect rate as our key performance measure although we will pay appropriate attention to the quantity of output.

It is still possible, however, that aggregate demand shocks could affect actual defect rate. Using the planned performance measures as a control for demand, reassuringly our regressions show that there is no statistically significant relationship between the actual defect rate and demand shocks. These results will be discussed in more details in the next section.

SCT uses a standard three-shift operation and each shift has six teams based on the location of the weaving rooms. Thus, there are a total number of eighteen teams. As shown in Table 1 , the average team size is around 10.5 with a standard deviation of 2.5. The weavers do not switch teams, but the composition of each team changes from week to week due to employee turnover and temporary absence. Our field research indicates that the firm does not use any systematic rule (explicit or implicit) on team assignment of new workers (such as assigning more able workers to teams which face more demanding assignments.) We will also confirm the suggested lack of systematic team assignment rules econometrically by testing the random team assignment hypothesis with the quantitative data below. 
Assuming that changes in team composition are not correlated with the error terms, we have an exogenous source of variation that can be used to test whether a weaver puts in more effort and improves her performance when she is working with more able peers. While working alongside her teammates, the weaver is responsible for her own output. There is no team production at the weaving section of SCT, and no externality is generated by the production technology. Moreover, on-the-job interactions among weavers are extremely limited by the working environment, because 1) each weaver is required to pay undivided attention to her machines and 2) the machines are loud and the weavers are wearing masks. Thus, any coworker effects could only come from either offline interactions or the simple presence of the teammates, or both.

SCT requires each of the 18 teams to hold team meetings during the meal break, once or twice a month to discuss issues concerning quality and exchange each other's experience of dealing with problems arising from production. Each team is also encouraged to hold "voluntary" team meetings after work as well. According to our own survey of all team leaders, nearly all teams meet once a week (four times a month). The average team meeting lasts about an hour. In addition, each team is required to hold a training session and skill contest after work at least once a week. The purpose of such sessions is to help each other enhance skill level. Finally, each team selects a model worker during one of their team meetings. The company provides select model workers with bonuses and paid vacations. For example, during 2002 just before our data collection began, about 40 model workers were selected and awarded with a trip to Singapore, Malaysia, and Thailand, staying at 3-star hotels. Through various team activities described above, each weaver becomes clearly aware of her performance relative to her teammates.

In the context of an urban Chinese enterprise, there is a powerful social divide between urban resident workers and rural migrant workers. The relaxation of the regulations on rural- 
urban migration in 1988 encouraged many rural workers to look for a job in the urban areas and get paid higher than what they earn from doing agricultural work at home. However, it is not easy for rural migrant workers to gain an urban housing registration ("hu kou"), which serves as a considerable entry barrier to the buoyant urban labor market for rural migrants, and causes inequality between the rural and urban labor force. Without urban housing registration, rural workers are ineligible for many high-paying urban jobs as well as the urban welfare programs such as healthcare and schooling (Huang, 2001). A rural worker must also pay for a temporary residence permit in order to find a legal residence in the urban areas. There is significant adjustment cost for a rural migrant to work in the urban area, which does not incur for an urban worker. The sharp distinction between the urban and rural status tends to create powerful group identities among rural migrant workers as well as among urban workers.

Our informant (HR director) confirms that social interactions happen differently for the rural and urban workers at SCT. The rural workers are mostly young single women from rural villages of Hebei Province. All of them live in the company dormitory free of charge ( 5 or 6 per room). After work they return to the same dorm, eat dinner in the same dining hall, and often socialize amongst themselves. It is thus highly likely that they create strong bonds among themselves, not only because they can relate more easily to each other, but also because they spend much more time together than with the urban workers. Since the rural workers form their own community, an urban worker will find it easier to be friends with other urban workers than breaking into the network of rural workers. Urban workers also prefer to communicate among themselves due to the commonality of their backgrounds (Nielsen, et. al., 2006 and Lu and Song, 2006).

While confirming that weekly wage for weavers are tied to their performance and days worked for the week, our informant does not mention that SCT has any explicit relative 
performance pay scheme. Nonetheless, the existence of skill contests and competition for model workers point to the presence of a tournament-style incentive for workers to outperform other workers, however small the size of the incentive may be. To explore any possible implicit incentive in wage payment for a weaver to outperform her teammates, we run a wage regression with two dummy variables indicating whether or not the weaver outperforms her teammate's average performance in DefRate ${ }_{\mathrm{it}}$ and DayOut ${ }_{\mathrm{it}}$ as additional explanatory variables (Outperforming Teammates' Avg DefRate ${ }_{i t}$ and Outperforming Teammates' Avg DayOut ${ }_{i t}$ ). As shown in Table 2, the fixed effect estimates of the wage equation first confirm our qualitative evidence from field research that individual wages are indeed related to own individual performance (DefRate ${ }_{i t}$ and DayOut ${ }_{i t}$ ) as well as days worked in a week (Days Worked $\mathrm{D}_{\mathrm{it}}$ ). Most importantly, however, the estimated coefficient on the outperformance dummy variable in DefRate $_{\text {it }}$ is positive and significant at the 1 percent level, suggesting an implicit pecuniary incentive for a weaver to outperform her teammates in DefRate. Although such reward may not be written explicitly in the wage contract, coworker effects would arise if the weavers are aware of the implicit competition. ${ }^{9}$

\section{Estimating coworker effects}

To study the nature of competition and cooperation among teammates at SCT, we draw on an empirical strategy used by a number of recent studies to estimate coworker effects in the workplace (see, for instance, Mas and Moretti, 2009, Bandiera, Barankay and Rasul, 2010, and Guryan, Kroft and Notowidigdo, 2009). ${ }^{10}$ Consider the following production function:

${ }^{9}$ To be consistent with the findings from our field research, there is no such incentive in DayOut. For more information on wage determination at SCT, see Dong, Jones and Kato (2007).

${ }^{10}$ Pioneering works using internal personnel data in economic research include Medoff and Abraham (1980), and Baker, Gibbs, and Holmstrom (1994a, 1994b). More recently, a number of studies (e.g., Lazear, 2000, Kleiner and Helper, 2003, Fernie and Metcalf, 1999, Paarsh and Shearer, 1999, Knez and Simester, 2001, 


$$
\mathrm{o}_{\mathrm{it}}=\mathrm{f}\left(\mathrm{a}_{\mathrm{i}}, \mathrm{e}_{\mathrm{it}}, \varepsilon_{\mathrm{it}}\right)
$$

where $\mathrm{o}_{\mathrm{it}}$ is the performance measure of weaver $\mathrm{i}$ in week $\mathrm{t}, \mathrm{a}_{\mathrm{i}}$ is her innate, time-invariant ability, $\mathrm{e}_{\mathrm{it}}$ is her effort in week $\mathrm{t}$, and $\varepsilon_{\mathrm{it}}$ is the error term. Weaver i's performance is determined by her innate time-invariant ability, her time-varying effort, and other time-varying random factors. Coworker effects are present if a weaver's effort is influenced by either the average effort of her teammates (how hard her teammates are working) or the average ability of her teammates (how capable her teammates are). We call the former "contemporaneous coworker effects" and the latter "compositional coworker effects". The contemporaneous effects are hard to identify due to the paucity of persuasive ways to separate $\varepsilon_{\text {it }}$ from $e_{i t}$. Our observed correlation between $o_{\text {it }}$ and $\overline{0}_{\text {-it }}$ (teammates' average performance excluding weaver i) could be due to correlation among the noises (for example, due to an aggregate demand shock.) Furthermore, regressing $\overline{\mathrm{o}}_{\text {-it }}$ on $\mathrm{o}_{\text {it }}$ suffers from the "reflection problem" (Manski 2003) where the direction of causality cannot be identified. Thus, the satisfactory identification of the "contemporaneous effects" requires an instrument that influences the coworkers' average performance while not affecting one's own performance. By definition, however, such an instrument does not exist, for every worker is a coworker of her colleagues at the same time.

The second type of coworker effects arises when changes in $\bar{a}_{\text {-it }}$ (her teammates' average innate ability excluding weaver i) caused by changes in her team composition will bring about changes in $e_{i t}$ (her own effort level). Such compositional coworker effects do not suffer the same econometric problems since neither the error term nor the worker's effort at time t should influence the innate ability of the coworkers. This is the approach taken by the aforementioned

Bandiera, Barankay and Rasul, 2005, and Shi, 2011), use such “insider” data and study the effects on individual worker performance of a change in pay methods (e.g., the switch from time rates to piece rates or to performance pay). A related line of work examines the effects on individual worker performance of the shift to team-based production (e.g. Batt, 1999, Hamilton, Nickerson and Owan, 2002, and Jones and Kato, 2011). None of these studies examine coworker effects and performance spillovers. 
recent studies and is also used in this paper.

There are a number of possible reasons why such compositional coworker effects may arise at SCT. Perhaps the most obvious reason is the presence of explicit and implicit incentives for weavers to outperform their coworkers at SCT (implicit relative performance incentive and model worker contest as described in some detail in the previous section). Second, as discussed in Mas and Moretti (2009), compositional coworker effects may arise from pro-social preferences and social pressure (disutility from behaving non-cooperatively and being viewed as behaving non-cooperatively by coworkers). Unlike in the case of supermarket cashiers in Mas and Moretti (2009), however, there is no obvious negative externality of underperformance in our case. Recall that there is no team production at SCT and that workers do not interact with their teammates while operating machines. As such, producing defective output from her assigned machines will make her teammates’ work no more difficult. As such, lagging behind itself does not constitute "behaving selfishly". In this sense, our weavers are similar to fruit pickers in Bandiera, Barankay and Rasul (2010). Nonetheless, unlike Bandiera, Barankay and Rasul (2010)'s fruit pickers, there is some externality through compensation schemes at SCT. Specifically, by lagging behind a weaver actually helps her coworkers earn more money through implicit relative performance incentive and increase their chances of winning the model worker contest. In other words, catching up with your coworkers can be viewed as "behaving selfishly" at SCT.

Third, it is certainly possible that coworker effects stem from knowledge sharing among coworkers. For instance, the newly-arrived "superstar” worker comes up with a new and better solution to a quality problem. Provided that she shares such a new and better solution with her coworkers, her coworkers will improve their performance. As discussed below, however, our results on interplay between group identities and coworker effects turn out to be inconsistent 
with knowledge sharing as a primary source of the coworker effect at SCT.

To estimate such compositional coworker effects successfully, we need to use a comprehensive set of covariates and predict with precision the true innate time-invariant ability of each individual weaver, $\mathrm{a}_{\mathrm{i}}$. To this end, we estimate the following equation with an extensive list of covariates:

$$
\text { DefRate }_{i t}=\alpha+\mathrm{a}_{\mathrm{i}}+\lambda \mathrm{M}_{\mathrm{it}}+\gamma \mathrm{C}_{\mathrm{jt}}+\beta \text { DayOut }_{\mathrm{it}}+\varepsilon_{\mathrm{it}}
$$

where $\mathrm{M}_{\mathrm{it}}$ is a set of 287 coworker dummy variables controlling for the presence of coworkers. For instance, the dummy variable "coworker1" in week $t$ takes a value of 1 if weaver $i$ works with weaver 1 in week $t$ in the same team, zero otherwise. $\mathrm{C}_{\mathrm{jt}}$ is the set of additional controls including week fixed effects and week times team fixed effects. DayOut ${ }_{i t}$ is included so that we can measure each weaver's ability to maintain high quality of the output, holding the quantity of the output constant. To see if endogeneity of DayOut ${ }_{i t}$ is a problem, we used planned DayOut ${ }_{i t}$ as an instrument for actual DayOut $\mathrm{it}_{\mathrm{t}}$. Reassuringly the results changes little in general and Hausman test cannot reject the null that the IV estimate of $\beta$ is not different from the OLS estimate of $\beta$. As such, we do not believe endogeneity poses any serious problem. ${ }^{11}$

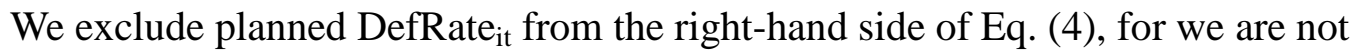
measuring the ability to outperform the plan. If high ability performers also get more demanding assignments, then controlling for planned performance would underestimate the spread in ability.

As we argued before, DayOut ${ }_{\mathrm{it}}$ is mostly demand-determined and individual weavers appear to have little room for discretionary effort to influence it. Hence, predicted innate ability differences in DayOut ${ }_{i t}$ are expected to be of less consequence for our analysis. However, we also estimated a similar equation to predict the true innate time-invariant ability of each

\footnotetext{
${ }^{11}$ As discussed earlier, we focus on DefRate as the only relevant performance measure for weavers at SCT. However, we also considered DayOut as an additional performance measures. As expected, considering DayOut as an additional performance measure was found to yield similar results. These as well as all other unreported results are available upon request from the authors.
} 
individual weaver in DayOut ${ }_{i t}$ as well. As expected, all of our results are insensitive to the inclusion of predicted innate ability of each individual weaver in DayOut ${ }_{\mathrm{it}}$.

Before turning to our main task of estimating coworker effects, we first need to check whether the abilities of the team members at a given time are correlated with each other. If they are, then our ability to identify the coworker effects will be constrained considerably.

Reassuringly our field research at SCT points to the absence of any rule (written or unwritten) of assigning the weaver to different teams based on her ability. To confirm the absence of such systematic assignment rule at SCT, we further test the random assignment hypothesis statistically. As shown in Appendix, the random assignment test turned out to support our field observation that there is random assignment.

We are now ready to specify our first-difference model which is used to estimate coworker effects:

(5) $\Delta$ DefRate $_{\text {it }}=\theta \Delta \bar{a}_{\text {-it }}+\kappa \Delta$ DayOut $_{\text {it }}+$ additional controls $+\Delta \varepsilon_{\text {it }}$

where $\Delta$ indicates the first difference between week $\mathrm{t}$ and $\mathrm{t}-1 . \bar{a}$-it is the average ability of weaver i's teammates who are working with her in the same team in week t. Specifically, $\bar{a}_{-\mathrm{it}}=\left(\sum_{k \neq i}^{m} \mathrm{a}_{\mathrm{k}}\right) / \mathrm{m}$

where $\mathrm{m}$ is the total number of weaver i' teammates who work with her in the same team in week t.

The value of $\theta$ measures the compositional coworker effects. DayOut $t_{i t}$ is included to control for pace of production and hence possible quantity-quality tradeoff (in theory a weaver can lower DefRate by simply slowing down her pace of production). To make sure that the estimated coefficient on $\Delta \bar{a}_{\text {-it }}$ is capturing the pure compositional coworker effect, we include a variety of additional controls. First, we include a set of variables controlling for demand, which 
include: Days worked ${ }_{i t}$, planned DefRate ${ }_{i t}$ and the total number of weavers working in the same team in week t. Planned DayOut ${ }_{i t}$ is excluded in equation because it is highly collinear with actual daily output, DayOut $i_{\text {it }}$ Second, we include constant (to capture a firm-wide time trend), individual fixed effects (to capture individual-specific time trends), month fixed effects and/or week fixed effects (to capture firm-wide time-specific effects), and month*team fixed effects (to capture team-specific time effects). Third, the positive compositional coworker effect $(\theta>0)$ means that when a weaver is working with more able teammates, she will put in more effort and improve her performance. However, for the same reason, her teammates also put in more effort and improve their performance. In other words, the positive compositional coworker effect will likely accompany an increase in average effort of her teammates which may cause her effort to rise and hence improve her performance through the contemporaneous coworker effect. As such, unless we control for average effort of her teammates, our estimates will be subject to omitted variable bias. To address this problem, we add $\Delta \bar{e}_{\text {-it }}$ as an additional control variable where $\bar{e}_{\text {-it }}$ is average effort of weaver i's teammates in week t (the effort level of each teammate, weaver $k$, is calculated by subtracting her estimated ability, $a_{k}$ from her DefRate $\left.{ }_{k t}\right)$.

The first difference model is preferred to the fixed-effect level model, for as discussed above, we cannot separate the underlying team fixed effects from the individual predicted abilities. Thus, in the level model, team fixed effects will show up on both sides of the equation causing spurious correlations.

Table 3 presents the OLS estimates of Eq. (5). We begin with presenting a parsimonious specification with no demand control in column (1). In column (2), we then add demand control and see if the results change. Column (3) presents an even less parsimonious specification with demand control and more detailed weekly time effects (instead of monthly time effects). Finally, in column (4) we further add team-specific time effects (Month*Team fixed effects) and explore 
the impact of such team-specific time effects on the coworker effect estimates.

For all four specifications, the estimates of $\theta$ (the effect of the change in teammates' average ability in defect rate on the change in the focal weaver's defect rate) are positive and statistically significant or close to being significant $(\mathrm{t}=1.59,1.40,1.97$, and 2.13), pointing to the presence of coworker effects at SCT. ${ }^{12}$ The size of the estimated coworker effect appears to be plausible and economically meaningful. When the average innate ability of her teammates to control quality improves by 0.1 percentage point (or a 0.1 percentage point decrease in DefRate ${ }_{i t}$ ) as a result of team compositional changes, the weaver's own defect rate will fall by 0.03 percentage points, ceteris paribus.

Finally, as expected, we find no evidence for the quality-quantity tradeoff (weavers reducing defect rate by simply slowing down the production pace). The estimated coefficients on DayOut $_{\text {it }}$ are small and in fact negative rather than positive.

\section{Coworker effects and Group Identity}

The most novel aspect of our data is the coexistence of the two distinct social networks in the workplace with strong group identities: Rural migrant network and urban resident network. We now explore how the presence of strong social networks (rural vs. urban) at SCT may be interacting with the observed coworker effect.

The nature and direction of such interplay between social networks/group identities and the coworker effect will vary, depending on the sources of the coworker effect. The possible interplay between social networks and contagious enthusiasm/role model is rather intuitive and straightforward. The coworker effect through contagious enthusiasm/role model is more likely to

\footnotetext{
${ }^{12}$ We followed Mas and Moretti (2009) and adjusted standard errors to take into account the sampling variability of the estimated fixed effects for coworkers, $\mathrm{a}_{\mathrm{k}}$. It turned out standard errors changed very little when we applied this adjustment.
} 
arise within the social network rather than across the social network. Again consider the arrival of the "superstar" worker to the team. The coworker effect through contagious enthusiasm/role model arises when an incumbent team member will be inspired by the arrival of the "superstar" worker and perhaps even start emulating her as a role model, resulting in better performance for herself. When the "superstar" worker is an ingroup worker as opposed to an outgroup worker, the incumbent team member is more likely to be inspired by her and try to emulate her as a role model. ${ }^{13}$

Likewise, the coworker effects stemming from knowledge sharing among teammates are also more likely to arise within the social network rather than across the network. First, as explained in Section II, there is little pecuniary incentive to share knowledge with teammates (in fact there are explicit and implicit incentives for a weaver to outperform her teammates and hence not to share knowledge) and as shown in the recent experimental literature on group identify and altruistic behavior, group identity helps workers overcome their self-interests and engage in knowledge sharing among workers within the social network. Second, the cost of knowledge sharing tends to be lower among workers within the same social network than across the network (e.g., rural migrant workers are from the same rural region and speak the same dialect, and literally eat and sleep in the same dorm).

In stark contrast, the coworker effects arising from competitive spirits and incentive are likely to be stronger across the social network as opposed to within the network. As discussed earlier, when a weaver finds herself competing with more able weavers in the workplace, she increases her effort and improve her own performance to satisfy her competitive spirit. We argue that in general her competitive spirit will be more acutely awaken when the increase in the

\footnotetext{
${ }^{13}$ The positive effects on student outcomes of having teachers of the same gender or race as role models are reported in the economics of education literature (see, for instance, Rask and Bailey, 2002; Dee, 2004; Bettinger and Long, 2005 for recent evidence).
} 
average ability of her teammates originates in her outgroup teammates (such as the arrival of the “superstar” worker who belongs to the other social network). In addition, the nature of group identity and social networks generated by the powerful divide between rural migrant and urban workers in Chinese factories makes the aforementioned competitive spirit story particularly relevant and compelling at SCT.

As discussed earlier, the deep rural/urban social divide causes weavers to form powerful group identity and a pervasive mentality of "us against them", resulting in informal yet vigorous intergroup competition within the team. In this context of intergroup competition, the arrival of new and able weaver from the other social network is viewed as a threat to the supremacy of her group over the other group (or the group’s plan to establish its supremacy without delay). ${ }^{14}$ Social pressure to respond strongly to such a threat to the status of the social network will be evoked. As discussed and supported by evidence in Mas and Moretti (2009), such social pressure prompts a weaver competing with more able outgroup teammates to exert herself more to satisfy her group's collective competitive spirit. The failure to do so may result in shame, reputational loss, and social sanctions.

When the increase in the average ability of her teammates comes from the rising average ability of ingroup teammates (e.g., the arrival of the "superstar" worker who belongs to her own social network), however, the aforementioned social pressure and collective competitive spirit are largely irrelevant. In fact, our weavers may display similar group identity-induced altruistic behaviors to what the recent experimental literature on group identity reports, when competing with their teammates in the presence of pecuniary incentives to outperform their teammates. Specifically, when competing with more able teammates, the weaver is less likely to win skill

\footnotetext{
${ }^{14}$ The relationship between inter-group competition and intra-group cooperation has been studied in experimental economics (see, for instance, Bornstein, Gneezy and Nagel, 2002, Tan and Bolle, 2007, and Reuben and Tyran, 2009).
} 
contest and model worker competition, and hence prizes, and her wage will be more likely to be lower since she is less likely to outperform the average performance of her teammates (as shown in our wage regression results). As such, there is an tournament-style incentive for her to respond to the rising ability of her teammates by putting in more effort and enhance her performance. However, she will not act on this incentive insofar as the source of the rising average ability of her teammates is the presence of more able ingroup teammates. In other words, a weaver may be willing to let her teammates win the prize and earn higher wages insofar as they belong to the group with which she strongly identifies. Such altruistic behaviors do not arise if the rising average ability of her teammates comes from more able outgroup teammates.

To explore the interplay between coworker effects and social networks, we modify Eq. (5) to allow for the interaction between coworker effects and social networks:

(6) $\Delta$ DefRate $_{\mathrm{ijt}}=\theta_{1} \Delta \bar{a}_{\text {-igt }}+\theta_{2} \Delta \bar{a}_{\text {-i-gt }}+\kappa \Delta$ DayOut $_{\text {it }}+$ additional controls $+\Delta \varepsilon_{\text {it }}$

where g denotes person i's social network, $\bar{a}$-igt is the average ability of weaver i’s ingroup teammates who are working with her in the same team in week t AND belong to the same social network. Likewise, $\bar{a}_{\text {-i-gt }}$ is the average ability of weaver i’s outgroup teammates who are working with her in the same team in week t AND do not belong to the same social network. We use the same set of control variables as in Eq. (5) except that our demand control includes the size of the rural and urban networks in the team separately (instead of controlling for the total team size).

The OLS estimates of Eq. (5) are presented in Table 4. The estimated coefficients on the average ability of outgroup teammates are positive and statistically significant at the 1 percent level, whereas the estimated coefficients on ingroup teammates are considerably smaller (one third to one half of those on the average ability of outgroup teammates) and not significant even 
at the 10 percent level. ${ }^{15}$ Again, the size of the estimated coworker effect from outgroup teammates is plausible and economically meaningful: when the average innate ability in quality control of her outgroup teammates improves by 0.1 percentage point (or a 0.1 percentage point

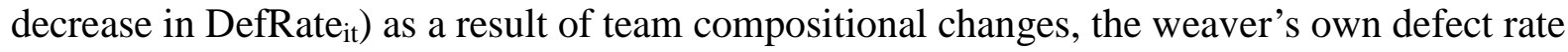
will fall by close to 0.03 percentage points, ceteris paribus. In short, we find evidence that the coworker effect exists across the network yet not within.

The regression results in Table 4 also suggest that our coworker effect estimates are unlikely to be driven by common noise that affect all teammates, for otherwise $\theta_{1}$ and $\theta_{2}$ should both be significant for both groups of workers who work in the same team.

Finally, we further explore whether such a coworker effect across the network is stronger among rural migrant workers than among urban resident workers. To this end, we divide the data into two subsamples, the rural migrant worker sample and the urban resident worker sample, and estimate Eq (6) for those two subsamples separately. Tables 5 and 6 present the results. For the rural migrant sample, as shown in Table 5, the estimated coefficients on the average ability of her outgroup teammates (or urban teammates) are positive and significant at the 1 percent level in the most parsimonious specification, and still significant at the 10 percent level even in the least parsimonious specification with team-specific time effects controlled for.

In contrast, the estimated coefficients on the average ability of her ingroup teammates (rural) are not significant and relatively small (especially when team-specific time effects are controlled for). In short, for the average rural migrant worker, changes in the average ability of her ingroup (rural) teammates are found to have little impact on her own effort, whereas she is found to put in more effort and improve her performance in output quality when the average ability of her outgroup (urban) teammates increases. The magnitude of such intergroup coworker

\footnotetext{
${ }^{15}$ The differences in the estimated coefficients between outgroup and ingroup are statistically significant or close to being statistically significant.
} 
effects appears to be again sensible and economically meaningful. For instance, as her outgroup (urban) teammates' average ability in quality control improves by 0.1 percentage point (or a 0.1 percentage point drop in DefRate $\mathrm{i}_{\mathrm{it}}$, the average rural migrant weaver will put in more effort and improve her own defect rate by 0.02 percentage points.

The results for the urban resident worker sample are similar to those for the rural migrant worker sample although they are somewhat less significant. The estimated coefficients on the average ability of the urban worker's outgroup teammates (rural) are positive and significant at the 10 percent level with team-specific time effects controlled for and close to being significant without team-specific time effects but with demand control ( $\mathrm{t}=1.58$ and 1.62). When demand control is not included, as shown in column (12), the estimated coworker effect is less significant $(t=31)$. The estimated coefficients on the average ability of her ingroup teammates (urban) are, however, much smaller and not at all significant. As such, similar to the case of rural workers, on the one hand, an urban weaver is found to change her effort level very little in response to a change in her ingroup (urban) teammates' average ability. On the other hand, she is found to put in more effort and lower her own defect rate by 0.03 to 0.04 percentage points when her outgroup (rural) teammates’ average ability rises by 0.1 percentage point. ${ }^{16}$

In sum, we find that the coworker effects arise amongst weavers across the social network rather than within the network. It follows that the coworker effects at SCT are likely to be driven by each weaver's competitive spirit in general and her collective competitive spirit in the presence of intergroup competition, combined with social pressure (shame, social sanctions and reputational damages), in particular. In contrast, the lack of significant coworker effects within the network suggests that contagious enthusiasm/role model and knowledge sharing may

\footnotetext{
${ }^{16}$ Unfortunately the differences in the coworker effects between ingroup and outgroup are no longer statistically significant once we slice the data into the two subsamples (rural and urban) and hence the data for each regression are considerably thinner.
} 
be of less relevant at SCT.

\section{$\underline{\text { V. Conclusions }}$}

Using weekly data for defect rates (proportion of defective output) for all weavers in a Chinese textile firm during a 12 months (April 2003-March 2004) period, this paper has provided some of the first rigorous evidence on the presence and nature of coworker effects in the manufacturing workplace. As in the case of U.S. supermarket cashiers studied by Mas and Moretti (2009), the coworker effects we detected for Chinese weavers are driven probably neither by knowledge sharing nor by contagious enthusiasm/role model, for if knowledge sharing and contagious enthusiasm/role model were key drivers of the coworker effect, we should have found more significant coworker effects within the social network rather than across the social network (and we have found the opposite pattern). However, unlike Mas and Moretti (2009)'s cashiers, our weavers do not impose any direct negative externality on their teammates by underperforming. In fact, there are explicit and implicit tournament-style incentives for them to outperform their teammates (or positive externality imposed on their teammates by underperforming). Hence social pressure (e.g., shame, reputational damage and social sanctions) to minimize negative externality imposed on her teammates by her own underperformance (which turned out to be the primary source of the coworker effects among cashiers in Mas and Moretti, 2009) is of less relevance to our weavers.

Instead we believe that strong group identity and intergroup competition have much to do with the coworker effect that we have observed. In the context of the pervasive divide between rural migrant workers and urban resident workers in the manufacturing workplace in Chinese cities, each weaver's competitive spirit is more powerfully awaken when the increase in the average ability of her teammates stems from the rising ability of her outgroup teammates as 
opposed to her ingroup teammates. The increase in the average ability of the worker's outgroup teammates is regarded as a threat to her group's relative standing against the other group. Hence there is social pressure for her (and all other ingroup teammates) to counter such a rise in the average ability of her outgroup teammates by putting in more effort and improving her performance.

Such competitive behavior is further amplified by the presence of explicit and implicit pecuniary incentive for each weaver to outperform her teammates. The rising average ability of the worker's ingroup teammates may stimulate her individual competitive spirit (which is also consistent with the presence of the aforementioned tournament-style incentives) yet such individual competitive spirit appears to pale compared to collective competitive spirit (or collective social pressure on each teammate to counter the rise in the average ability of her outgroup teammates).

A recent study of fruit pickers in the U.K. (Bandiera, Barankay and Rasul, 2010) reports stronger coworker effects within the network than across the network. Group identity of their fruit pickers appears to be largely personal and certainly not based on deep-rooted social and historical institutions (such as rural migrant versus urban resident workers in our case), it is quite possible that intergroup competition (the "us versus them" mentality) which prevails between rural migrant and urban resident workers in the workplace in Chinese factories may not be as pervasive among those fruit pickers. Such lack of powerful intergroup competition among fruit pickers may account for their contrasting finding.

The recent experimental economics literature on group identity reports evidence on the significant role of group identities in overcoming self-interests and facilitating altruistic behaviors. Our workers are found to be willing to let their teammates win the prize and earn higher wages insofar as they belong to the group with which they strongly identify. Such 
altruistic behaviors are found to be missing when the rising average ability of their teammates comes from more able outgroup teammates. As such, this paper has presented some of the first field evidence from the actual workplace on the role of group identities in promoting altruistic behaviors.

Lastly, our finding on the presence of strong inter-group competition implies that coworker effects may be stronger in the integrated workplace than in the segregated workplace, and that inter-network competition in the integrated workplace may lead to better overall performance in the integrated workplace than in the segregated workplace. ${ }^{17}$

${ }^{17}$ Charness and Villeval (2009), based on new experimental evidence, draws a similar implication for the advantage of workplace diversity in the context of mixing senior with junior workers. In addition, Kurtulus (2011) uses subjective evaluations of individual workers as performance measures and provide evidence for the performance-enhancing effect of workplace diversity in terms of gender, narrowly-defined tenure within division, education and wage. 
References

Akerlof, George A. and Kranton, Rachel E. "Economics and Identity." Quarterly Journal of Economics, 2000, 115(3), pp. 715-53.

Baker, George; Gibbs, Michael and Holmstrom, Bengt. "The Internal Economics of the Firm: Evidence from Personnel Data." Quarterly Journal of Economics, 1994a, 109(4), pp. 881-919.

. "The Wage Policy of a Firm." Quarterly Journal of Economics, 1994b, 109(4), pp. 921-55.

Bandiera, Oriana; Barankay, Iwan and Rasul, Imran. "Social Incentives in the Workplace." Review of Economic Studies, 2010, 77(2), pp. 417-58.

. "Social Preferences and the Response to Incentives: Evidence from Personnel Data." Quarterly Journal of Economics, 2005, 120(3), pp. 917-62.

Bartel, Ann P.; Ichniowski, Casey and Shaw, Kathryn. "Using "Insider Econometrics' to Study Productivity." American Economic Review, 2004, 94(2), pp. 217-27.

Batt, Rosemary. "Work Organization, Technology, and Performance in Customer Service and Sales." Industrial and Labor Relations Review, 1999, 52(4), pp. 539-64.

Bettinger, Eric P. and Long, Bridget Terry. "Do Faculty Serve as Role Models? The Impact of Instructor Gender on Female Students." American Economic Review, 2005, 95(2), pp. 152-57.

Bornstein, Gary; Gneezy, Uri and Nagel, Rosmarie. "The Effect of Intergroup Competition on Group Coordination: An Experimental Study." Games and Economic Behavior, 2002, 41(1), pp. 1-25.

Charness, Gary and Villeval, Marie-Claire. "Cooperation and Competition in Intergenerational Experiments in the Field and the Laboratory." American Economic Review, 2009, 99(3), pp. 956-78.

Chen, Yan and Li, Sherry Xin. "Group Identity and Social Preferences." American Economic Review, 2009, 99(1), pp. 431-57.

Dee, Thomas S. "Teachers, Race, and Student Achievement in a Randomized Experiment." Review of Economics and Statistics, 2004, 86(1), pp. 195-210.

Dong, Xiao-yuan; Jones, Derek C. and Kato, Takao. "Experience, Productivity, Teams and Wages: An Empirical Analysis Using Panel Data on Individual Worker Output," IZA Discussoin Paper 3122, 2007.

Falk, Armin and Ichino, Andrea. "Clean Evidence on Peer Effects." Journal of Labor Economics, 2006, 24(1), pp. 39-57.

Fernie, Sue and Metcalf, David. "It's Not What You Pay It's the Way That You Pay It and That's What Gets Results: Jockeys' Pay and Performance." Labour, 1999, 13(2), pp. 385411.

Gibbons, Robert. "Incentives and Careers in Organizations," Advances in Economics and Econometrics: Theory and Applications: Seventh World Congress. Volume 2. Cambridge; New York and Melbourne: Cambridge University Press, 1997, 1-37.

Guryan, Jonathan; Kroft, Kory and Notowidigdo, Matthew J. "Peer Effects in the Workplace: Evidence from Random Groupings in Professional Golf Tournaments." American Economic Journal: Applied Economics, 2009, 1(4), pp. 34-68.

Hamilton, Barton H. ; Nickerson, Jack A. and Owan, Hideo. "Team Incentives and Worker Heterogeneity: An Empirical Analysis of the Impact of Teams on Productivity and Participation." Journal of Political Economy, 2003, 111(3), pp. 465-98. 
Hansen, Daniel G. "Worker Performance and Group Incentives: A Case Study." Industrial and Labor Relations Review, 1997, 51(1), pp. 37-49.

Huang, Youqin. "Gender, Hukou, and the Occupational Attainment of Female Migrants in China (1985-1990)." Environment and Planning A, 2001, 33(2), pp. 257-79.

Ichniowski, Casey and Shaw, Kathryn. "Insider Econometrics: A Roadmap for Estimating Empirical Models of Organizational Design and Performance," R. Gibbons and J. Roberts, Handbook of Organizational Economic. 2008, fothcoming.

Ichniowski, Casey; Shaw, Kathryn and Prennushi, Giovanna. "The Effects of Human Resource Management Practices on Productivity: A Study of Steel Finishing Lines." American Economic Review, 1997, 87(3), pp. 291-313.

Jones, Derek C. and Kato, Takao. "The Impact of Teams on Output, Quality and Downtime: An Empirical Analysis Using Individual Panel Data." Industrial and Labor Relations Review, 2011, 64(2), pp. 215-40.

Kleiner, Morris and Helper, Susan. "Changing Incentives for Production Employees: Impacts on Establishment Economic Outcomes and Worker Satisfaction," Paper presented at the 55th IRRA meeting, Washington, D.C., 2003.

Knez, Marc and Simester, Duncan. "Firm-Wide Incentives and Mutual Monitoring at Continental Airlines." Journal of Labor Economics, 2001, 19(4), pp. 743-72.

Kurtulus, Fidan Ana. "What Types of Diversity Benefit Workers? Empirical Evidence on the Effects of Co-Worker Dissimilarity on the Performance of Employees." Industrial Relations, 2011, 50(4), pp. 678-712.

Lazear, Edward P. "Performance Pay and Productivity." American Economic Review, 2000, 90(5), pp. 1346-61.

Lu, Zhigang and Song, Shunfeng. "Rural-Urban Migration and Wage Determination: The Case of Tianjin, China." China Economic Review, 2006, 17(3), pp. 337-45.

Mas, Alexandre and Moretti, Enrico. "Peers at Work." American Economic Review, 2009, 99(1), pp. 112-45.

Medoff, James L. and Abraham, Katharine G. "Experience, Performance, and Earnings." Quarterly Journal of Economics, 1980, 95(4), pp. 703-36.

Nielsen, Ingrid; Nyland, Chris; Smyth, Russell; Zhang, Mingqiong and Zhu, Cherrie Jiuhua. "Effects of Intergroup Contact on Attitudes of Chinese Urban Residents to Migrant Workers." Urban Studies, 2006, 43(3), pp. 475-90.

Paarsch, Harry J. and Shearer, Bruce S. "The Response of Worker Effort to Piece Rates: Evidence from the British Columbia Tree-Planting Industry." Journal of Human Resources, 1999, 34(4), pp. 643-67.

Rask, Kevin N. and Bailey, Elizabeth M. "Are Faculty Role Models? Evidence from Major Choice in an Undergraduate Institution." Journal of Economic Education, 2002, 33(2), pp. 99-124.

Rueben, Ernest and Tyran, Jean-Robert. "Everybody Is a Winner: Promoting Cooperation through All Can Win Intergroup Competition," IZA Discussion Paper No. 4112, 2009.

Shi, Lan. "Incentive Effect of Piece-Rate Contracts: Evidence from Two Small Field Experiments." B.E. Journal of Economic Analysis and Policy: Topics in Economic Analysis and Policy, 2010, 10(1).

Tan, Jonathan H. W. and Bolle, Friedel. "Team Competition and the Public Goods Game." Economics Letters, 2007, 96(1), pp. 133-39. 


\section{Appendix: Random assignment}

Since weavers do not switch teams, their predicted abilities also include team fixed effects, for instance as the different teams may be producing different textile products. Thus, we cannot identify whether a more able worker is assigned to a more able team, as the abilities are measured on different scales across the teams. We can, however, test whether a high-ability weaver is working with other high-ability teammates at any given time.

Guryan, Kroft and Notowidigdo (2009) point out that the typical estimate of regressing the teammates' average ability at time t on one's own ability is biased downward, for one cannot be assigned to herself. In other words, the pool of peers that the teammates at time t are drawn from have a lower average ability for a high-ability focal worker than for a low-ability worker, as the focal worker is excluded from the otherwise identical pool. The bias is more severe when the pool is small. Following the bias-correction method in Guryan, Kroft and Notowidigdo (2009), we run the following regression:

(A1) $\mathrm{a}_{\mathrm{it}}=\pi_{0}+\pi_{1} \bar{a}_{-\mathrm{i}}+\pi_{2}\left(\bar{a}_{-\mathrm{it}}-\bar{a}_{-\mathrm{i}}\right)+$ team fixed effects $+\mathrm{v}_{\mathrm{it}}$

where $\mathrm{a}_{\mathrm{it}}$ is the predicted ability in defect rate of weaver $\mathrm{i}$ who shows up in week $\mathrm{t}, \bar{a}_{\text {-it }}$ is the average ability of her teammates who are actually working with weaver $\mathrm{i}$ in week $\mathrm{t}$, and $\bar{a}_{-\mathrm{i}}$ is the average ability of all of weaver i's teammates including those not working in week $\mathrm{t}$ (in other words, counting any weaver who works with weaver i at least one time during the time period under study). By construction, $\mathrm{a}_{\mathrm{i}}=\bar{\alpha} \mathrm{N}-\bar{a}_{\text {-i }}(\mathrm{N}-1)$ where $\bar{\alpha}$ is the average ability of the whole team including weaver $\mathrm{i}$ and $\mathrm{N}$ is the total number of weavers in the team, counting any weaver who works with weaver i in the same team for at least one week during the time period under study) Thus $\pi_{1}$ should be close to the mean of $-(\mathrm{N}-1)$. We calculated $\mathrm{N}$ for each of the 18 teams from the data, which turned out to be around 16 . Hence, $\pi_{1}$ should be about -15 . The coefficient 
$\pi_{2}$ indicates whether more able workers are matched with other more able teammates at time $t$, holding the average ability of the pool that the teammates are drawn from constant. The null hypothesis of random assignment means that $\pi_{2}$ is zero.

Columns (1) and (2) in Table A1 present the regression results. As expected, $\pi_{1}$ is significant at the 1 percent level and close to -15 , and more importantly we cannot reject the null that $\pi_{2}=0$, supporting our field observation that there is random assignment. The results are robust to the inclusion of week fixed effects. In sum, the random assignment test turned out to support our field observation that there is random assignment. 
Table 1 Summary statistics

\begin{tabular}{lrrr}
\hline \hline & \multicolumn{3}{l}{ Std. } \\
& Mean & \multicolumn{1}{l}{ Dev. } & $\mathrm{N}$ \\
\hline DefRate $_{\text {it }}$ (percent) & 0.239 & 0.181 & 9966 \\
DayOut $_{\text {it }}$ (in 10 meters) & 54.555 & 18.285 & 9966 \\
Days Worked $_{i t}$ & 6.271 & 0.88 & 9966 \\
Wage $_{i t}$ & 148.136 & 30.369 & 9966 \\
Female $_{i}$ & 0.969 & 0.175 & 287 \\
Rural $_{i}$ & 0.666 & 0.473 & 287 \\
Team Size $_{\text {it }}$ & 10.458 & 2.481 & 953 \\
\hline \hline
\end{tabular}

Source: All data provided by SCT.

Notes: See text for variable definitions. Subscripts i, j, and t indicate weaver i, team j, and week t. Since no weaver switched teams during the time period under study, variations in Team Size $\mathrm{j}_{\mathrm{jt}}$ come from labor turnover and temporary absence. 
Table 2 Relationship between performance measures and weekly wages: Dep=Wage $\mathrm{C}_{\mathrm{it}}$

\begin{tabular}{lllll}
\hline \hline & $(1)$ & $(2)$ & $(3)$ & $(4)$ \\
\hline DefRate $_{i t}$ & $-9.946^{* * *}$ & $-9.247^{* * *}$ & $-10.260^{* * *}$ & $-9.466^{* * *}$ \\
& $(3.54)$ & $(3.50)$ & $(3.65)$ & $(3.57)$ \\
DayOut $_{\text {it }}$ & $0.079^{* * *}$ & $0.078^{* * *}$ & $0.086^{* * *}$ & $0.083^{* * *}$ \\
& $(3.29)$ & $(3.39)$ & $(3.44)$ & $(3.46)$ \\
Days Worked $_{\text {it }}$ & $24.816^{* * *}$ & $24.632^{* * *}$ & $24.912^{* * *}$ & $24.770^{* * *}$ \\
& $(49.73)$ & $(47.74)$ & $(48.94)$ & $(47.18)$ \\
Outperforming Teammates' Avg DefRate $_{\text {it }}$ & $6.768^{* * *}$ & $6.446^{* * *}$ & $6.776^{* * *}$ & $6.461^{* * *}$ \\
& $(10.79)$ & $(11.23)$ & $(10.86)$ & $(11.30)$ \\
Outperforming Teammates' Avg DayOut $_{i t}$ & 0.402 & 0.424 & 0.335 & 0.400 \\
& $(0.63)$ & $(0.68)$ & $(0.52)$ & $(0.63)$ \\
Time FE & Month & Month & Week & Week \\
Month*Team FE & No & Yes & No & Yes \\
\hline Adj.R-squared & 0.734 & 0.751 & 0.733 & 0.750 \\
$\mathrm{~N}$ & 9961 & 9961 & 9961 & 9961 \\
\hline \hline
\end{tabular}

Source: All data provided by SCT.

Notes: See text for variable definitions. Absolute values of $t$ are in parentheses. All standard errors are robust and clustered at the individual level. All models include individual fixed effects as well as the following controls: Teammates' Avg DefRate ${ }_{i t}$ (mean of weaver i' teammates’ DefRate);

Teammates' Avg DayOut ${ }_{i t}$ (mean of weaver i' teammates' DayOut); planned DayOut for weaver i in week t, and the number of all weavers working in the same team as weaver $\mathrm{i}$ in week $\mathrm{t}$.

$* \mathrm{p}<0.10$

** $\mathrm{p}<0.05$

$* * * \mathrm{p}<0.01$ 
Table 3 Coworker effects: Dep $=\Delta$ DefRate $_{i t}$

\begin{tabular}{lllll}
\hline \hline$\Delta \bar{a}_{\text {-it }}$ & $(1)$ & $(2)$ & $(3)$ & $(4)$ \\
& 0.273 & 0.270 & $0.333^{* *}$ & $0.323^{* *}$ \\
$\Delta$ DayOut $_{\text {it }}$ & $(1.59)$ & $(1.40)$ & $(1.97)$ & $(2.13)$ \\
& $-0.004^{* * *}$ & $-0.005^{* * *}$ & $-0.004^{* * *}$ & $-0.004^{* * *}$ \\
Demand control & $(15.85)$ & $(19.02)$ & $(18.67)$ & $(18.62)$ \\
Time FE & No & Yes & Yes & Yes \\
Month*Team FE & Month & Month & Week & Week \\
\hline Adj.R-squared & No & No & No & Yes \\
$\mathrm{N}$ & 0.075 & 0.096 & 0.119 & 0.112 \\
\hline \hline
\end{tabular}

Source: All data provided by SCT.

Notes: $\bar{a}_{\text {-it }}$ is the average ability of weaver i's teammates in week t. See text for the remaining variable definitions. Absolute values of t are in parentheses. All standard errors are robust; clustered at the individual level; and adjusted to take into account the sampling variability of the estimated fixed effects for coworkers, following Mas and Moretti (2009). All models include individual fixed effects and $\Delta$ (teammates' average effort).

$* \mathrm{p}<0.10 * * \mathrm{p}<0.05 * * * \mathrm{p}<0.01$ 
Table 4 Coworker effects and social networks: Dep $=\Delta$ DefRate $_{\text {it }}$

\begin{tabular}{lllll}
\hline \hline & $(1)$ & $(2)$ & $(3)$ & $(4)$ \\
\hline$\Delta \bar{a}_{\text {-igt }}$ & 0.086 & 0.091 & 0.104 & 0.077 \\
$\Delta \bar{a}_{\text {-i-gt }}$ & $(1.10)$ & $(1.06)$ & $(1.21)$ & $(0.87)$ \\
& $0.279^{* * *}$ & $0.256^{* * *}$ & $0.248^{* * *}$ & $0.245^{* * *}$ \\
$\Delta$ DayOut $_{\text {it }}$ & $(3.31)$ & $(2.99)$ & $(2.86)$ & $(2.67)$ \\
& $-0.004^{* * *}$ & $-0.004^{* * *}$ & $-0.004^{* * *}$ & $-0.004^{* * *}$ \\
Demand control & $(15.90)$ & $(19.29)$ & $(17.90)$ & $(18.67)$ \\
Time FE & No & Yes & Yes & Yes \\
Month*Team FE & Month & Month & Week & Week \\
\hline Adj.R-squared & No & No & No & Yes \\
N & 0.075 & 0.096 & 0.119 & 0.112 \\
\hline \hline
\end{tabular}

Source: All data provided by SCT.

Notes: $\bar{a}_{\text {-igt }}$ is the average ability of weaver i's ingroup teammates in week $\mathrm{t}$ and $\bar{a}_{\text {-i-gt }}$ is the average ability of weaver i's outgroup teammates in week t. See text for the remaining variable definitions. Absolute values of $t$ are in parentheses. All standard errors are robust; clustered at the individual level; and adjusted to take into account the sampling variability of the estimated fixed effects for coworkers, following Mas and Moretti (2009). All models include individual fixed effects and $\Delta$ (teammates' average effort).

$* \mathrm{p}<0.10 * * \mathrm{p}<0.05 * * * \mathrm{p}<0.01$ 
Table 5 Coworker effects and social networks: sample=rural migrant workers; Dep= $\Delta$ DefRate $\mathrm{it}_{\mathrm{it}}$

\begin{tabular}{lllll}
\hline \hline & $(1)$ & $(2)$ & $(3)$ & $(4)$ \\
\hline$\Delta \bar{a}_{\text {-igt }}$ & 0.103 & 0.141 & 0.121 & 0.055 \\
$\Delta \bar{a}_{\text {-i-gt }}$ & $(1.12)$ & $(1.45)$ & $(1.27)$ & $(0.54)$ \\
& $0.241^{* * *}$ & $0.189^{* *}$ & $0.178^{* *}$ & $0.171^{*}$ \\
$\Delta$ DayOut $_{\text {it }}$ & $(2.88)$ & $(2.24)$ & $(2.01)$ & $(1.76)$ \\
& $-0.003^{* * *}$ & $-0.004^{* * *}$ & $-0.004^{* * *}$ & $-0.004^{* * *}$ \\
Demand control & $(13.47)$ & $(15.54)$ & $(15.31)$ & $(16.20)$ \\
Time FE & No & Yes & Yes & Yes \\
Month*Team FE & Month & Month & Week & Week \\
\hline Adj.R-squared & No & No & No & Yes \\
$\mathrm{N}$ & 0.061 & 0.079 & 0.099 & 0.088 \\
\hline \hline
\end{tabular}

Source: All data provided by SCT.

Notes: $\bar{a}_{\text {-igt }}$ is the average ability of weaver i's ingroup teammates in week $\mathrm{t}$ and $\bar{a}_{\text {-i-gt }}$ is the average ability of weaver i's outgroup teammates in week t. See text for the remaining variable definitions. Absolute values of $t$ are in parentheses. All standard errors are robust; clustered at the individual level; and adjusted to take into account the sampling variability of the estimated fixed effects for coworkers, following Mas and Moretti (2009). All models include individual fixed effects and $\Delta$ (teammates' average effort).

$* \mathrm{p}<0.10 * * \mathrm{p}<0.05 * * * \mathrm{p}<0.01$ 
Table 6 Coworker effects and social networks: sample=urban resident workers; $D e p=\Delta$ DefRate $_{\text {it }}$

\begin{tabular}{lllll}
\hline \hline & $(1)$ & $(2)$ & $(3)$ & $(4)$ \\
\hline$\Delta \bar{a}_{\text {-igt }}$ & 0.113 & 0.073 & 0.165 & 0.161 \\
$\Delta \bar{a}_{\text {-i-gt }}$ & $(0.79)$ & $(0.53)$ & $(1.17)$ & $(0.95)$ \\
& 0.268 & 0.343 & 0.345 & $0.391^{*}$ \\
$\Delta$ DayOut $_{\text {it }}$ & $(1.31)$ & $(1.58)$ & $(1.62)$ & $(1.77)$ \\
& $-0.004^{* * *}$ & $-0.005^{* * *}$ & $-0.004^{* * *}$ & $-0.004^{* * *}$ \\
Demand control & $(8.59)$ & $(11.13)$ & $(10.41)$ & $(10.14)$ \\
Time FE & No & Yes & Yes & Yes \\
Month*Team FE & Month & Month & Week & Week \\
\hline Adj.R-squared & No & No & No & Yes \\
$\mathrm{N}$ & 0.092 & 0.114 & 0.155 & 0.129 \\
\hline \hline
\end{tabular}

Source: All data provided by SCT.

Notes: $\bar{a}_{\text {-igt }}$ is the average ability of weaver i's ingroup teammates in week $\mathrm{t}$ and $\bar{a}_{\text {-i-gt }}$ is the average ability of weaver i's outgroup teammates in week t. See text for the remaining variable definitions. Absolute values of t are in parentheses. All standard errors are robust; clustered at the individual level; and adjusted to take into account the sampling variability of the estimated fixed effects for coworkers, following Mas and Moretti (2009). All models include individual fixed effects and $\Delta$ (teammates' average effort).

$* \mathrm{p}<0.10 * * \mathrm{p}<0.05 * * * \mathrm{p}<0.01$ 
Table A1 Random assignment within a team: Dep $=a_{\text {it }}$

\begin{tabular}{lll}
\hline \hline & $(1)$ & $(2)$ \\
\hline $\bar{a}_{-i}$ & $-14.796 * * *$ & $-14.792 * * *$ \\
$\bar{a}_{-i}-\bar{a}_{\text {-it }}$ & $(48.94)$ & $(48.74)$ \\
& 0.003 & -0.005 \\
Week FE & $(0.32)$ & $(0.54)$ \\
Team FE & No & Yes \\
\hline Adj.R-squared & Yes & Yes \\
$\mathrm{N}$ & 0.998 & 0.998 \\
\hline \hline
\end{tabular}

Source: All data provided by SCT.

Notes: $\bar{a}_{\text {-it }}$ is the average ability of weaver i's teammates in week t. $\bar{a}_{-\mathrm{i}}$ is the average ability of all of weaver i's teammates including those not working in week $t$ (in other words, counting any weaver who works with weaver $i$ at least one time during the time period under study). Absolute values of $t$ are in parentheses. All standard errors are robust and clustered at the team level.

$* \mathrm{p}<0.10 * * \mathrm{p}<0.05 * * * \mathrm{p}<0.01$ 